Pobrane z czasopisma Wschód Europy http://journals.umcs.pl/we Data: 26/04/2023 01:08:43

DOI:10.17951/we.2020.6.1.55-71 Wschód Europy • Восток Европы • East of Europe vol 6, 1 / 2020

Христина Кобелева

ORCID ID: https://orcid.org/0000-0002-5335-0421

Воронежский государственный университет, Россия

\title{
Политический генотип гражданского общества России: прошлое и настоящее
}

\section{Актуальность исследования}

На сегодняшний день гражданское общество рассматривается как сложная, целостная система, отражающая наиболее значимые черты современного общества в целом. Кроме того, в современной политической науке актуализируется изучение возможностей развития и институционализации гражданского общества не по так называемому «западному образцу», а в ином социокультурном контексте. В связи с этим, требуется анализ специфики российской цивилизации через обращение к институциональным основаниям гражданского общества современной России, а также учёт преемственности между дореволюционной Россией и Советским Союзом, Советским Союзом и постсоциалистической Россией. Кроме того, особый интерес представляют проблемы, связанные со способностью российского общества к самоорганизации и автономизации от государства, с развитием субъектов, формирующих гражданское общество, с выяснением характеристик современного типа гражданского общества, т. е. всего круга проблем, решение которых предопределят вектор развития страны.

Политическая теория и практика доказали, что в периоды глубоких системных преобразований, когда институциональные изменения не находят прочной субъективной основы, актуализируются вопросы о возможностях и адаптивности политической культуры, её, так называемом, " «политическом генотипе». На сегодняшний день опубликовано немало научных работ, посвященных исследованию природы политического генотипа России, его особенностей, в которых по-разному рассматриваются политические традиции, нормы, менталитет россиян ${ }^{1}$.

1 Л. Г. Бызов, Контуры новорусской трансформации. Социокультурные аспекты формирования современной российской нации и эволюиия социально-политической системы, Москва, 2013; 
Стоит отметить, что особенности политического генотипа обусловливают сущность и модель гражданского общества, внутреннюю природу культуры и проявляются в политических традициях и механизмах передачи культурных ценностей, норм и образцов поведения. Поэтому предметом нашего исследования стали основы политического генотипа гражданского общества и политической культуры России, которые, в совокупности, определяют логику, векторы и перспективы развития страны, а также в центре внимания - социокультурная и политическая обусловленность российской модели гражданского общества. Без проведения подобного анализа невозможно рассмотрение вопросов состояния гражданского общества в России в современный период, поскольку элементы гражданского общества базируются на тех принципах общежития, которые имеют многовековую историю и складывались постепенно, с соблюдением традиций. Ведь культурно-цивилизационное своеобразие общества, определяемое той или иной устойчивой доминирующей системой ценностей, непосредственно влияет на жизнедеятельность граждан и находит отражение в массовом сознании и поведении граждан.

Поэтому перспективу развития гражданского общества в современной России следует рассматривать с учётом уже укрепившихся в менталитете россиян национальных культурно-исторических и политических традиций, а не только с позиций западничества. Обращение к культурно-политическому своеобразию России необходимо, поскольку новая государственность и гражданское общество формируются, опираясь на базовые, первичные структурные элементы массового национального сознания, на традиционные социокультурные и политические ценности общества, и, в целом, особенности политического генотипа россиян. При этом учёт объективных тенденций мирового развития показывает, что не требуется отказ от собственных генотипических особенностей, разрушение цивилизационных основ. Более того, как показывает практика модернизации некоторых стран (Китая, Японии и других) именно на национальной самобытной основе могут быть сформированы прочные основы для формирования и развития гражданского общества, без «слепого копирования» западного образца. Многообразие цивилизационно-культурных типов предопределило разные формы становления и развития гражданских отношений в современных условиях.

Цель данной статьи показать роль социокультурных особенностей политического генотипа и основ гражданских отношений России, обоснование роли

А. В. Лукин, П. В. Лукин Умом Россию понимать. Постсоветская политическая культура и отечественная история, Москва, 2015; Н. А. Омельченко, История государственного управления в России, Москва, 2005; Д. Фурман, Движение по спирали. Политическая система России в ряду других систем, Москва, 2010; Н. В. Карпова, Социология политической культуры современной России, Москва, 2012, с. 9-12 и др. 
Pobrane z czasopisma Wschód Europy http://journals.umcs.pl/we

Data: 26/04/2023 01:08:43

Политический генотип гражданского общества России: прошлое и настоящее

и значения государственного начала для институционализации гражданского общества.

В данной статье под «политическим генотипом» мы будем понимать сложную систему взаимосвязанных и взаимодействующих между собой элементов, определяющих состояние, возможности изменчивости, развития, а также степень адаптации политической культуры конкретного общества к новым внутренним и внешним вызовам.

Методологической основой исследования указанной проблематики стал социокультурный анализ цивилизационной специфики России, обусловленной своеобразием культуры и политического генотипа, предполагающий в первую очередь выделение и комплексное осмысление институциональных и неинституциональных сторон гражданской жизни. При этом культура рассматривается как основа и условие возникновения и существования институциональных структур гражданского общества современного типа.

\section{Исторические детерминанты и современные вызовы}

В настоящее время наше внимание к проблематике политического генотипа обусловлено тем, что первые десятилетия XXI века в России стали характеризоваться усилением консервативных тенденций, отказом от западных либеральных концепций развития. В политическом и бытовом дискурсе снова актуализировалась проблематика «самобытного пути развития Российского государства». Стало очевидным, что массовое сознание россиян, став амбивалентным в период крайней нестабильности 1990-х годов, снова возвращается в свое уже привычное традиционное русло. Данное обстоятельство обусловлено «усталостью» россиян от резких, подчас непродуманных, преобразований/реформ.

К тому же потребность в стабильности актуализировала ориентацию общества на «наведение порядка в стране сильной рукой». Именно «порядок и стабильность», а не «демократия и гласность», снова стали доминирующей идеологемой в сознании российских граждан, а могущество страны устойчиво связывается с сильным авторитарным и авторитетным лидером. В настоящее время даже демократически настроенные граждане допускают возможность ограничений политических и гражданских прав и свобод в целях борьбы с экстремизмом, преступностью и коррупцией, указывая на важность и опасность данных угроз стабильности страны.

Обращаясь к гражданскому обществу, необходимо принять во внимание то, что в России и на Западе были созданы неодинаковые условия для его формирования. Так, в развитых странах Запада (например, в Англии, Франции, Германии, США) оно проходило на основе эволюционного развития, иначе говоря, «органической модернизации», и постепенного накопления демократических традиций, экономических и политический свобод, их институционализации и закрепления в массовом сознании граждан. В России же формирование структурных элементов гражданского общества чаще происходило в условиях, когда 
на предшествующих этапах развития страны утверждался резкий разрыв между декларированными, формальными принципами (например, относительно прав и свобод человека) и реально сложившимися общественными отношениями.

Как следствие, архаическое, эклектичное политическое сознание российского общества оказывалось органически неспособным к восприятию, пониманию и усвоению либеральных и демократических ценностей, моделей поведения, тормозило формирование «демократии участия».

Поэтому мы считаем, что современной России нельзя слепо копировать западный опыт и механически переносить его на национальную российскую «почву», на которой он не всегда приживётся. Но, с другой стороны, многовековую удачную практику других стран необходимо использовать, учитывая при этом специфику российского общества, российской государственности и их взаимоотношений. Важно лишь не допускать в этом ни бездумного подражательства, ни высокомерной замкнутости.

Стоит отметить, что по поводу наличия в России предпосылок формирования гражданского общества существуют различные точки зрения. Так, одни видят основания российского гражданского общества в крестьянской общине, православной идеологии и, соответственно, требуют восстановления соборности, общинности и других, на их взгляд, позитивных и присущих только русским черт дооктябрьского прошлого; другие считают, что гражданского общества в пространствах Российской империи и СССР не существовало и его нужно формировать «с нуля». Правда, и здесь нет единства: то ли нужно опираться на опыт Запада, воспринимая «готовые» идеи, принципы и институты, то ли отказаться от этого, демонстрируя самобытность и опираясь на традиции с учётом российских реалий ${ }^{2}$. При этом не стоит забывать, что идеал гражданского общества на различных этапах истории России тоже имел свои особенности.

Во-первых, государственное начало в России, по крайней мере с XV-XVI вв. являлось главным двигателем общественных процессов. Именно государство в России стало создавать или «разрешать» те или иные ячейки гражданского общества. Но именно оно же тормозило их деятельность, что затрудняло закрепление в психологии русского человека привычки к самостоятельному, инициативному поведению.

Во-вторых, недостаточное развитие частной собственности, стимулов для сельскохозяйственного труда, предпринимательства.

B-третьих, общинность и реформы, задумывавшиеся сверху, укрепляли многовековую традицию россиян (вероятно, идущую от татаро-монгольского

2 В. Т. Пуляев, Движение к гражданскому обществу: российский вариант, „Социально-гуманитарные знания”, 2000, № 1; T. Nicols, Russian democracy and social capital, „Social science information”, Vol. 35, № 4, 1996, p. 634; N. Ohr, Social capital in Rural Russia: legacies of the soviet era, The Kennan' Institute for advanced Russian studies, Washington, 26-27 September, 1997, p. 1; В. В. Петухов, Политическая активность и гражданская самоорганизация россиян, „Общественные науки и современность", 2002, № 6, с. 63; и др. 
Pobrane z czasopisma Wschód Europy http://journals.umcs.pl/we

Data: 26/04/2023 01:08:43

периода) склоняться перед властью, с большей готовностью исполнять приказы, чем проявлять инициативу. При этом традиция авторитарной централизованной власти и готовность граждан подчиняться ей существует и в современной России.

Россия, уходящая истоками своей культуры в Византийскую империю, на многие столетия установила единовластие князя, сменившееся затем самодержавием царя и переросшее в культ личности вождя в обществе. Поэтому естественным и закономерным выглядит сформировавшийся в менталитете россиян персонифицированный образ власти в лице харизматического лидера, который обеспечивает единство политической воли и наведение общественного порядка. Все политические решения и контроль исходят от одного человека и зависимой от него клиентелы. При этом политические организации и учреждения играют роль подчиненных.

Высокая концентрация и централизация власти в период глубоких системных кризисов, войн, способствовала достижению единства и стабильности, поскольку опиралась на развитой административный аппарат и силовые структуры, обеспечивающие единоначалие и подчиненность людей на огромных территориях и при сложном полиэтническом составе населения.

Как следствие, в России уровень доверия граждан к главе государства всегда был выше, чем к политическим институтам. В этом находит своё отражение патернализм политического сознания россиян. Когда люди не доверяют никому, они, наверное, делегировали бы полномочия на уровень богов. Для россиян таким последним уровнем делегирования выступает глава государства. Можно сказать, что в России господствует «самодержавная» политическая культура, ключевая характеристика которой - властецентричность как движущая сила исторического процесса. Именно в национальном или региональном лидере заключалась сакральность и символичность политической власти в России.

В тоже время, стоит отметить, что россияне увеличили список требований к лидеру, за которыми они готовы пойти. В частности, теперь указывается, что он должен проявлять уважение к людям (народу), честность, способность признавать свои ошибки, действовать в интересах народа, должен не понаслышке знать, как живут люди, быть демократичным и миролюбивым. Тогда как в предыдущие годы россияне обычно называли лишь твердость, целеустремленность, жесткость, обаяние ${ }^{3}$.

Однако несмотря на наличие персонифицированного доверия к лидеру в политическом генотипе россиян, стоит отметить, что данное доверие - это не константа и не постоянная величина, а лишь своеобразный «кредит доверия», в котором может быть отказано, если лидер начинает принимать непопулярные решения и не считается с запросами/требованиями народа. В подтверждение

3 Перелом в сознании уже произошел, https://newsland.com/user/4297807604/content/perelom-vsoznanii-uzhe-proizoshel/6597030 (дата обращения 12.01.2019). 
этому приведём данные опросов общественного мнения россиян. Так, за 2014 год доверие россиян к президенту Владимиру Путину выросло с 55 до 79\%. Об этом говорится в исследовании доверия россиян к институтам власти «Левада-центра». Согласно итогам опроса, количество не доверяющих В. Путину в России уменьшилось с 42 до 17\%. В мае 2014 г. рейтинг президента РФ В. Путина и партии «Единая Россия» достиг исторического максимума. По данным опроса ВЦИОМ, проведенного 10-11 мая 2014 г., рейтинг одобрения деятельности В. Путина составил 85,9\%. Как показывают опросы, столь высокий уровень одобрения работы президента зафиксирован, в первую очередь, в связи со сложной ситуацией в Украине (эти события назвали главными $52 \%$ респондентов) ${ }^{4}$. Однако в октябре 2018 г. рейтинг доверия к президенту России В. В. Путину составил лишь 58\%: по сравнению с 2017 г. он упал на 17\%. В целом, этот показатель снизился до уровня 2013 г. Заметное падение рейтинга президента социологи отметили еще в начале 2018 г. Президентские выборы в марте 2018 г. несколько «оживили» этот показатель, но после выборов вместо обещанного повышения зарплат люди получили лишь повышение пенсионного возраста, что не нашло поддержки и одобрения со стороны народа. Как следствие, к концу декабря 2018 г. рейтинг В. В. Путина оказался на уровне $36,5 \% 5$.

В условиях политической и экономической нестабильности 1990-х гг. у россиян вновь появилась ностальгия по «жёсткому правлению», «сильной руке», что нашло отражение в высоком уровне доверия к институту президентства, авторитет которого резко возрос с приходом к власти В. В. Путина. Например, в ноябре 2016 г. 35\% россиян считали, что народу постоянно нужна «сильная рука». Еще $37 \%$ уверены, что бывают такие ситуации, когда нужно сосредоточить всю полноту власти в одних руках. И только $21 \%$ полагали, что ни в коем случае нельзя допускать того, чтобы вся власть была отдана в руки одного человека'.

В декабре 2018 г. руководитель «Левада-Центра» Лев Гудков отметил, что, согласно соцопросам, В.В. Путин в сознании россиян продолжает оставаться «безальтернативным лидером, хотя уровень его поддержки упал примерно на четверть». В то же время, «та конструкция, которая имеет место в сознании россиян

4 http://obozrevatel.com/politics/98237-doverie-rossiyan-k-putinu-za-god-vyiroslo-s-55-do-79.htm (Опрос проведен 19-22 сентября 2014 года по репрезентативной всероссийской выборке городского и сельского населения среди 1600 человек в возрасте 18 лет и старше в 134 населенных пунктах 46 регионов страны. Распределение ответов приводится в процентах от общего числа опрошенных вместе с данными предыдущих опросов. Статистическая погрешность данных этих исследований не превышает 3,4\%) (дата обращения 12.10.2014).

5 Подробнее см.: Доверие политикам, ВЦИОМ, 2019, Январь. режим доступа: https://wciom. ru/news/ratings/doverie_politikam (дата обращения: 10.01.2019); Рейтинг доверия к Путину вернулся к уровню 2013 года, „Ведомости”, 04.10.2018, режим доступа: https://www.vedomosti. ru/politics/news/2018/10/04/782769-reiting-doveriya-k-putinu (дата обращения: 28.11.2018).

6 Власть и общество, Левада-Центр, 2016, дек. Режим доступа: http:// www.levada.ru/2016/12/12/ vlast-i-obshhestvo (дата обращения: 21.07.2017). 
и которая состоит в том, что наша страна нуждается в сильной руке, сохраняется для почти 80\% населения». Из них 58\% опрошенных считают, что сильный лидер нужен нашей стране всегда, а в таких особых ситуациях, как сейчас, потребность в таком лидере испытывают еще $21 \%$ населения. При этом, $79 \%$ российских респондентов считают, что сильный лидер нужен, потому что «только он в состоянии контролировать бюрократию и защитить страну от врагов», в окружении которых, по мнению 81\% населения, она находится. Существующее недовольство и раздражение россияне по-прежнему переносят на другие уровни и ветви власти, а также различные министерства ${ }^{7}$.

Однако стоит обратить внимание и на другую особенность: для менталитета россиян характерна подозрительность, настороженное отношение к представителям власти, государственным структурам и в то же время, подчас «слепое» доверие к обещаниям политиков о лучшей жизни. Как верно отметил знаменитый русский философ Н.А. Бердяев, «русским свойственна мысль о священном помазании власти, но им же свойственна мысль, что всякая власть есть зло и грех». Поэтому «русский народ одновременно является государственно-деспотическим и анархически-свободолюбивым» ${ }^{8}$.

Подобная амбивалентность, противоречивость русского национального характера на протяжении всей истории оказывает влияние на уровень институционального доверия. Чаще всего россияне заведомо воспринимают государственный аппарат как неизбежное, но необходимое зло. Поэтому низкий уровень доверия граждан к большинству политических институтов страны уже давно стал «общим местом» во всех социологических исследованиях, касающихся этой темы. Как следствие, большинство россиян не ориентируются и не хотят ориентироваться в «хитросплетениях» государственных структур, дублирующих друг друга службах, их непрерывной борьбе за перераспределение компетенций.

К тому же, очевидная «нелюбовь» россиян к политическим институтам, настороженное и критическое отношение к институциональным инновациям, также имеет свои исторические корни. Ведь «традицией русского реформаторства, - констатируют авторы исследовательского проекта, посвящённого российской политической культуре и повседневности, - является такое воздействие на макроуровень социетальной системы, которое игнорирует последствия влияния её изменившихся структурных свойств для микроуровня системы» ${ }^{9}$. Это означает, что новые институты и учреждения, как правило, изначально не были ориентированы на учёт традиционных ориентаций сознания и поведения россиян, и не соответствовали практикам повседневности. В данном случае недоверие к ним

7 Подробнее см.: Перелом в сознании уже произошел, https://newsland.com/user/4297807604/ content/perelom-v-soznanii-uzhe-proizoshel/6597030 (дата обращения: 12.01.2019).

8 Н. А. Бердяев, Истоки и смысл русского коммунизма, Москва, 1990, с. 15, 350.

9 3.А. Грунт, Н.А. Кертман, Т.В. Павлова, С.В. Патрушев, А.Д. Хлопин, Российская повседневность и политическая культура: проблемь обновления, „Политические исследования”, 1996, № 4, c. 52-64. 
со стороны граждан указывало на поверхностный характер осуществляемой властями политики «догоняющей неорганической» модернизации.

Возвращаясь к историческому экскурсу, стоит отметить, что элементом гражданского общества в своё время являлась община, поскольку в Древней Руси XI-XII вв. она оставалась незыблемой и за несколько десятилетий с начала XII в. настолько окрепла, что пересилила княжескую власть, подчинив её полностью вечу. В новгородской и псковской политической жизни того времени просматриваются атрибуты гражданского общества. По существу, здесь вече было носителем верховной власти. Оно выбирало всех должностных лиц. Князь был лишь наёмным должностным лицом.

В середине XVI в. в России появились Земские соборы, основой деятельности которых являлось коллегиальное управление. Одни считают, что при всём своём несовершенстве Земские соборы являлись одним из элементов гражданского общества, выступали политическим оппонентом единовластия в России. При Иване IV Грозном окончательно утверждается царский режим, суть которого состояла во всеобщем и безусловном подчинении ему всех сословий и всех властей. Но и в этих условиях возникает первое самоуправление на местах. Это - губернское и земское самоуправление, избираемое сельской общиной. Однако некоторые ученые считают, что сущность земского самоуправления XVI в. заключалась не столько в самоуправлении, сколько в выполнении государственных приказных поручений, перекладывавшихся с военно-служилых людей на местных выборных. И в таком виде земское самоуправление не служило и не могло служить основой для формирования гражданского общества в России.

В эпоху царствования Петра I появляются коллегии, Сенат. Екатерина II допускает созыв городских собраний. Но, вероятно, о «зарождении» элементов гражданского общества можно говорить не ранее последней трети XVIII в. В период царствования Александра I возникают отдельные сферы гражданской жизни, не связанные с государством. Частная жизнь светского общества начинает протекать в салонах, клубах и других относительно самостоятельных учреждениях. После реформ Александра II гражданское общество формируется в виде земств, различных союзов предпринимателей. Кроме того, начался процесс становления среднего класса - социальной базы гражданского общества. Средний класс быстро пополнялся за счёт дворянства, которое после реформы 1861 г. в большинстве своём разорилось и вынуждено было искать другие источники дохода. В условиях огосударствления общественной жизни николаевской России дворянство могло занять пустующее место организованной буржуазии, ставшей на Западе основой гражданского общества. Но дворянство оказалось не способным исполнить нетрадиционную для себя роль.

Император Николай II не желал поделиться властью с нарождавшимся третьим сословием и осуществлять назревшие реформы вместе с владельцами капитала, промышленниками и фабрикантами. Но в то же время, российская история знала и думский парламентаризм. Хотя Государственным Думам в России 
Pobrane z czasopisma Wschód Europy http://journals.umcs.pl/we

Data: 26/04/2023 01:08:43

Политический генотип гражданского общества России: прошлое и настоящее

начала ХХ в. не везло (три из четырёх были распущены самодержавием), они всё же проделали немалую положительную работу. Так, первый двухпалатный «парламент», появившийся в России в начале XX в., несмотря на сословную ограниченность и узость своей компетенции, являлся представительным учреждением народа, в котором действовала оппозиция, выдвигавшая альтернативные пути демократического развития страны. Но война 1914 г. обострила все противоречия российского общества и государства и привела к революционному изменению политического строя.

Октябрьская революция 1917 г., по существу, не затронула принципов организации общества, но вместо сословной структуры была введена статусная. Общество, как и прежде, основывалось на отношениях власти. Правящим классом стала партийная номенклатура, присвоившая себе право распоряжаться средствами производства. Остальное население превратилось в государственно-зависимых работников. В силу незрелости гражданского общества государство оказалось единственной силой, способной решить проблемы форсированной индустриализации, культурной революции, сохранить целостность и независимость страны.

В 1917 г. в России основой нового общественного и государственного строя стали Советы. До 1936 г. Советы избирались непосредственно на предприятиях. Депутаты Советов находились в зависимости от своих избирателей, получали от них наказ. Имела место система отзыва депутатов. Но постепенно в силу разных причин объективного и субъективного порядка (ожесточённая борьба за власть, подмена советских органов партийными, принижение роли депутатов и др.) основы гражданского общества подверглись ограничениям, а затем были лишены своего главного предназначения - обеспечивать условия для решения самим народом своих собственных проблем. Некоторые ученые считают, что именно отсутствие эффективно действующего гражданского общества в Советской России способствовало установлении и закреплению тоталитарного режима в стране.

В социалистической общественной системе элементы гражданского общества были поставлены государством в такие условия, при которых возможность их функционирования как полноправного актора была блокирована самим фактом существования социалистического государства. Вот почему эти элементы в большинстве своём формировались, прежде всего, как феномен, целью которого было уничтожение социалистического государства. Не борьба с отдельными недостатками государственного аппарата, не улучшение имеющегося типа социальной реальности, а полное разрушение всей системы общественного строя с диктатом всесильного государства - вот что стало целью многих элементов гражданского общества.

Отсутствие условий для нормального существования в легальной сфере общественной жизни, а также реальных перспектив когда-нибудь этих условий достигнуть привели к искажению их сущности, гипертрофировав и абсолютизировав столь несвойственную любому нормально функционирующему гражданскому обществу функцию разрушения. 
Однако советская политическая культура тоже возникла «не на пустом месте», а вобрала в себя многие черты и установки культуры самодержавия. Благодаря различным временным наслоениям, она стала сложным, эклектичным и противоречивым образованием. Советская политическая культура формировалась под влиянием радикальных общественных изменений, в результате которых образовалось совершенно особое политическое сообщество, в котором преобладало политически зависимое сообщество граждан и культивировались командные формы партийного руководства, жесткого государственного контроля. Это была культура мобилизационного типа, обслуживающая форсированную модернизацию страны.

Вместе с тем в ней присутствовал и комплекс конструктивных идей и практик в виде высокой социальной активности и мобильности народа, стремительного роста его образовательного и культурного потенциала. Наряду с авторитарными чертами, в ней содержались идеи свободы, ориентации на социальное равенство и справедливость. Традиционная установка на политический порядок и сильную государственную власть не препятствовала формированию широких общественных движений и актуализации проблемы самовыражения.

После роспуска КПСС в стране возникли партии, которые были лишены исторической преемственности и соответствующего политического опыта, что сразу же определило их ограниченные возможности эффективно выполнять функцию посредника между властью и обществом. Многовековые «государственнические» традиции России продолжали доминировать.

Таким образом, в период существования СССР в гражданском обществе как институте, обеспечивающим гражданские, политические и экономические права индивида, не было необходимости, поскольку оно ослабило бы процесс управления. Поэтому гражданское общество, как один из источников, порождающих стихийность, было фактически исключено из общественной жизни, лишено статуса гаранта демократии. В данном случае особенность политического генотипа гражданского общества в России состоит в том, что вышедшее из недр административно-бюрократической системы, оно находится в аморфном состоянии. В силу этого, несмотря на демонтаж тоталитарных институтов, доминирование политической системы над гражданским обществом продолжается.

\section{Особенности политического генотипа России}

Как отмечал Н. А. Бердяев, «размеры русского государства ставили русскому народу почти непосильные задачи, держали русский народ в непомерном напряжении. Требования государства слишком мало оставляли свободного избытка сил. Вся внешняя деятельность шла на службу государству». Поэтому в психологию русского народа «вошли и безграничность русского государства, и безграничность русских полей» ${ }^{10}$.

10 Н.А. Бердяев, Истоки и смысл русского коммунизма, Москва, 1990, с. 18. 
Эти замечания Н. А. Бердяева показывают, что демократические ценности не могут легко и быстро войти в менталитет российского народа после многовекового существования страны в условиях системы жесткой политической власти. Это нашло свое подтверждение в современной политической истории России. Государство в России по-прежнему воспринимается народом как становой хребет цивилизации, гарант целостности существования общества, устроитель жизни, а власть - не как субъект обслуживания общества, а как средоточие национальной миссии, исполнение которой является общей задачей представителей власти и народа.

Так, согласно данным опроса, проведенного Левада-Центром в ноябре 2016 г., 64\% россиян считают Россию «великой державой», тогда как в 1999 г. лишь $31 \%$ респондентов. При этом демократическим государством с рыночной экономикой Россию хотели бы видеть 33\% опрошенных. Такую же часть составляют те, кому «все равно, лишь бы была стабильность». Государством с особым устройством и самобытным путем развития видят Россию $16 \%$ респондентов. Социалистическим государством с коммунистической идеологией - $11 \%$. Империей с абсолютной монархией (как до 1917 г.) - 3\% ${ }^{11}$.

Поэтому политическое и культурное единство и равенство по-прежнему рассматривается как субстанциональное начало всего общества. В этих условиях принятые властью основополагающие политические решения предполагают легитимацию со стороны общества, коллективную деятельность и общую ответственность за результаты. Социум становится при этом активным исполнителем и проводником государственной политики, гарантом ее эффективности и справедливости. Все другие социальные единицы лишаются какой-либо автономности и самостоятельности. Это в полной мере относится к общественным группам и отдельной личности. Они полностью зависимы и равны в своей подчиненности власти. Между ними не существует принципиальных различий в отношении провозглашенных политических целей и обязанностей. Политическая свобода, разнообразие позиций или протест здесь не предполагаются. Подобное единообразие вызывает справедливые возражения. Однако нивелирующее всех политическое единение и общность судьбы в различные исторические периоды помогли стране сохранять жизнестойкость и преодолеть огромные трудности и испытания.

Ещё одной отличительной чертой политического генотипа многие исследователи называют коллективизм, общинность, солидарность, которые сейчас тесно связывают с понятием «социальный капитал». Они выражают социальное единство и сплоченность граждан, взаимную поддержку и помощь. Главными формами существования социального капитала в России всегда были семья, тесные родственные и дружеские связи, а отнюдь не общественные организации.

11 Державность и особый путь России, Левада-Центр, 2016, Дек. Режим доступа: http://www. levada.ru/2016/12/12/derzhavnost-i-osobyj-put-rossii (дата обращения: 11.07.2017). 
Принято считать, что в период существования СССР были созданы огромные запасы социального капитала, но с начала 1990-х гг. началось его систематическое «разрушение».

Одной из причин этого процесса стала резкая ломка прежней (советской) системы ценностей, которые выступали в качестве системообразующих и консолидирующих общество. Политики - либералы, пришедшие к власти в стране в начале 1990-х гг. - направили все усилия на дискредитацию данной системы ценностей. При этом они практически ничего не сделали для того, чтобы новая (западная лишь по названию) система ценностей стала органичной частью современного российского общества, а не вступала бы в противоречие с нравственными установками и нормами большинства граждан. Обществу не было предложено цельной, непротиворечивой системы ценностей. Поэтому на сегодняшний день можно наблюдать мозаичность и эклектичность системы ценностей россиян, где происходит столкновение и соединение традиционного и современного, западного и восточного.

Можно сказать, что российское общество до сих пор не смогло оправиться от «травмы». Конец травмы означал бы формирование цельной и органичной системы ценностей: норм, правил, символов и убеждений, т.е. новой культуры, в которой будет закодирована новая традиция, предназначенная для передачи новым поколениям. Это означает новую групповую идентичность. Но очевидно, что в российском обществе ещё полностью не завершён «реабилитационный период» после «травмы», полученной в 1990-е гг. и новая, объединяющая всех граждан, система ценностей до сих пор не сформирована.

Как следствие, социальная атомизация российского общества не преодолена, «приращение» социального капитала в стране осуществляется крайне медленно. Ведь для того, чтобы «внести вклад» в социальный капитал, человеку необходимо адаптироваться к моральным нормам определённого сообщества и усвоить господствующую в нём систему ценностей, правил и норм. В противном случае, человек в своей повседневной деятельности будет поступать эгоистически, «играть по своим правилам», пренебрегая нормами общественной морали. В данном случае можно говорить о накоплении лишь, так называемого, «негативного» социального капитала и усилении межличностного недоверия в обществе.

Большую роль в развитии и укреплении межличностного недоверия среди граждан России сыграл приобретённый ими в 1990-е гг. опыт «выживания» в условиях крайней политической и социально-экономической нестабильности, беззакония, научивший людей во всём рассчитывать лишь на свои силы. Невыполненные обещания политиков, резкое ухудшение материального положения большинства граждан, крушение «финансовых пирамид» и т.п. лишь усилили тенденцию к развитию межличностного и институционального недоверия. В целом, за последние годы резко сузился «радиус доверия», в том числе, в отношении родственников. 
По справедливому замечанию российского учёного В.В. Петухова, «российский индивидуализм - это индивидуализм людей, столкнувшихся с тяжелыми проблемами выживания, поэтому он и не дает пока импульсов к различным формам гражданской и профессиональной консолидации и солидаризма». Если на макроуровне «власть будет замкнута на саму себя, решать свои проблемы в ущерб общественным, то и на микроуровне наиболее ярко будет проявляться адаптационный индивидуализм, не считающийся ни с чем, кроме собственной выгоды» ${ }^{12}$.

Значительный отпечаток на процесс формирования гражданского общества накладывает также форсированный характер процесса модернизации в современной России, когда в сжатые сроки одновременно решаются задачи, доставшиеся от исторически различных этапов. Изменение материального положения различных групп населения приводит к слишком быстрой и радикальной трансформации социальной структуры. Это обстоятельство порождает напряженность и конфликты государства с различными социальными группами.

К тому же, финансовый диктат делает независимые масс-медиа всё более ангажированными, поэтому зачастую «голос» гражданского общества почти не слышен. Предприятия среднего и мелкого бизнеса, которые составляют «живую ткань» гражданской жизни, либо поглощаются крупными, сращенными с государственным аппаратом финансово-промышленными группами, либо умирают под действием налогового и финансового прессинга государственной власти. В результате уничтожается конкурентоспособный сектор «малой экономики», а вместо главных принципов гражданской жизни (конкуренции, индивидуализации и сотрудничества) утверждается монополизм экономической и политической власти.

Кроме того, по своей сущности гражданское общество имеет этнорегиональный характер и, пожалуй, нигде это не ощущается столь отчётливо, как в евразийской полиэтнической России. Разрыв в степени зрелости и по уровню развития гражданских отношений в различных регионах слишком велик (достаточно сравнить, к примеру, жизнь в мегаполисах типа Москвы, Санкт-Петербурга и существование в глубинке Приморского края). Указанное обстоятельство затрудняет развитие гражданского процесса на политическом пространстве современной России.

\section{Выводы}

Таким образом, как видим, в России неразвитость институтов гражданского общества, патернализм россиян, низкий уровень развития и неэффективность системы самоуправления, «самодержавность» власти, бюрократический характер государственного управления сохраняются и воспроизводятся на различ-

12 В.В. Петухов, Политическая активность и гражданская самоорганизация россиян, „Общественные науки и современность”, 2002, № 6, с. 59-65. 
ных этапах политической истории страны. Поэтому самому государству также многое предстоит сделать, чтобы оно могло стать гарантом поступательности процесса развития гражданского общества в современной России, создать надёжные правовые, экономические, политические и культурные предпосылки для самореализации индивидов и групп. Но если на макроуровне власть будет замкнута на саму себя, решать свои проблемы в ущерб общественным, то и на микроуровне наиболее ярко будет проявляться адаптационный индивидуализм, не считающийся ни с чем, кроме собственной выгоды. В этом случае «накопление» социального капитала будет происходить крайне медленно, а уровень институционального и межличностного доверия будет стабильно низким.

Не подлежит сомнению, что состояние политической культуры определяется не только современными общественными процессами, но и всем историческим опытом, который накоплен обществом и запечатлен в универсальных и константных ценностях, нормах и способах политического самоопределения. При этом, как мы увидели, в российском политическом генотипе можно обнаружить ценности восточного и западного типа, традиционалистские и модернистские установки, стремление к инновациям, но в то же время сохранение традиционных устоев.

Таким образом, все структурные составляющие образуют определенный синтез и обусловливают качественное своеобразие российской политической культуры, способствуя самоидентификации российского общества, выбору своего цивилизационного пути развития. Более того, как мы увидели, гражданское общество не является для России чем-то чуждым и невостребованным. Оно естественно и органично, но основы его формирования и конкретные формы воплощения на практике, вне всякого сомнения, были иными, чем на Западе.

Поэтому в контексте изучения постсоциалистических трансформаций с учётом социокультурной исключительности, можно сформировать новый подход к анализу эндогенных и экзогамных источников процессов формирования, развития и институционализации гражданского общества как в современной России, так и в странах бывшего, так называемого, «соцлагеря», принимая во внимание различия в модернизации стран как закономерные, естественные и неизбежные. 
Pobrane z czasopisma Wschód Europy http://journals.umcs.pl/we

Data: 26/04/2023 01:08:43

Политический генотип гражданского общества России: прошлое и настоящее

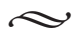

Аннотация: Цель данной статьи - исследование генотипических особенностях формирования гражданского общества в контексте развития российской социально-политической системы, а также генотипические истоки российской политической культуры, которые определяют логику и перспективы ее развития. Отмечено, что генотипические особенности обусловливают внутреннюю природу политической и правовой культуры и проявляются в традициях и механизмах передачи культурных ценностей, норм и образцов, моделей поведения граждан. В статье анализируются основные формы проявления политического генотипа гражданского общества России, раскрывается «генетический» механизм политико-культурной преемственности.

Ключевые слова: гражданское общество, государство, менталитет, политический генотип, политические ценности, политическая культура, политические традиции, политическое развитие, социальный капитал, доверие

\section{Genotyp polityczny społeczeństwa obywatelskiego Rosji: przeszłość i teraźniejszość}

Streszczenie: Celem pracy była analiza problemu cech genotypowych kształtowania się społeczeństwa obywatelskiego w kontekście zmian w rosyjskim systemie społeczno-politycznym, genotypowego tła rosyjskiej kultury politycznej, które wpływa na logikę i perspektywy jej rozwoju. Wyraźne, genotypowe osobliwości określają wewnętrzny charakter kultury politycznej i prawnej i przejawiają się w tradycjach i mechanizmach przekazywania wartości kulturowych, norm i modeli, wzorców zachowań obywateli. Artykuł analizuje główne formy istnienia rosyjskiego społeczeństwa politycznego, genotyp oraz badany "genetyczny" mechanizm sukcesji kultury politycznej.

Słowa kluczowe: społeczeństwo obywatelskie, państwo, mentalność, genotyp polityczny, wartości polityczne, kultura polityczna, tradycje polityczne, rozwój polityczny, kapitał społeczny, zaufanie

\section{Political genotype of Russia 's civil society: past and present}

Abstract: The purpose of the research was to analyze the issue of genotype' features of formation civil society in the context of the Russian socio-political system changes, the genotypic background of Russian political culture which influences the logic and prospects of its development. Marked, the genotypic peculiarities determine the inner nature of political and legal culture and are manifested in the traditions and mechanisms of transmission of cultural values, norms and models, citizen behavior patterns. In this article analyzing the main forms of existence of Russian civil society's political genotype and explored «genetic» mechanism of political culture succession.

Keywords: civil society, state, mentality, political genotype, political values, political culture, political traditions, political development, social capital, trust 


\section{Источники и литература}

\section{Монографии}

Berdyayev N.A., Istoki i smysl russkogo kommunizma, Moskva 1990.

Civil society and government, ed. by N. L. Rosenblum, R. C. Post, Princeton; Oxford: Princeton University Press, 2002, $408 \mathrm{p}$.

Democracies in flux: the evolution of social capital in contemporary society, ed. by R. D. Putnam, Oxford: Oxford University Press, 2004, $516 \mathrm{p}$.

Freeland C., Sale of the century: the inside story of the second Russian revolution, Boston, 2000.

Howard M. M., The weakness of civil society in Post-Communist Europe, Cambridge, UK; N.Y.: Cambridge University Press, 2003, 206 p.

\section{Научные статьи}

Batalov E., Politicheskaya kul'tura Rossii skvoz' prizmu civic culture, „Pro et Contra”, Leto 2002, T. 7, № 3. Busova N., Kul'turnyye korni sotsial'nogo kapitala, "Sotsiologicheskiye issledovaniya”, 1999, № 8, c. 144-148.

Demkiv 0., Kontseptsiya gruppovogo sotsial'nogo kapitala i eyë adaptatsiya k otechestvennym usloviyam, „Sotsiologiya: teoriya, metody, marketing", 2005, № 4, c. 104-118.

Dowley K.M., Silver B. D., Social Capital, Ethnicity and Support for Democracy in the Post_Communist States, Europe-Asia Studies, 2002, Vol. 54, № 4, p. 505-527.

Gaman-Golutvina 0. V., 0 stolknovenii moral'nogo i nravstvennogo nachal v rossiyskoy politike „Politicheskiye issledovaniya", 2005, № 3, c. 163-171.

Kobeleva Kh. A., Grazhdanskoye obshchestvo skvoz' prizmu osobennostey politicheskogo genotipa Rossii, Vestnik VGU, Seriya: Istoriya. Politologiya. Sotsiologiya, Voronezh: Izd-vo VGU, 2018, № 1, c. 100-103.

Kobeleva Kh. A., Institutsional'noye doveriye v sovremennoy Rossii: problemy i perspektivy, [v:] Razvitiye politicheskikh institutov i protsessov: zarubezhnyy i otechestvennyy opyt: materialy VI Vserossiyskoy nauchno-prakticheskoy konferentsii s mezhdunarodnym uchastiyem (24 aprelya 2015g. g. Omsk), otv. Redaktor I. A. Vetrenko, Omsk: Izdatel'stvo Omskogo gos. un-ta, 2015, 418 s.

Kobeleva Kh.A., Fenomen personifitsirovannogo doveriya $v$ sovremennoy politike, [v:] Lichnost' $v$ sotsiume, gosudarstve, istorii: materialy Odinnadtsatoy regional'noy nauchnoy konferentsii (g. Voronezh, 1 fevralya 2017 g.), pod obshch. red. V. N. Glaz'yeva; Voronezhskiy gosudarstvennyy universitet, Voronezh: Izdatel'skiy dom VGU, 2017, c. 366-370.

Lapkin V.V., Pantin V.I., Osvoyeniye institutov i tsennostey demokratii ukrainskim i rossiyskim massovym soznaniyem. Predvaritel'nyye itogi, „Politicheskiye issledovaniya”, 2005, № 1, c. 50-62.

Mishler W., Rose R., What are the origins of political trust? Testing institutional and cultural theories in Post-Communist societies, "Comparative political studies", 2001, № 1 February, Vol. 34, p. 30-62. Petukhov V. V., Politicheskaya aktivnost' i grazhdanskaya samoorganizatsiya rossiyan, „Obshchestvennyye nauki i sovremennost"', 2002, № 6, c. 59-65.

Putnam R. D., Bowling alone: America's declining social capital, "Journal of democracy", 1995, Vol. 6, № 1, January. 
Pobrane z czasopisma Wschód Europy http://journals.umcs.pl/we

Data: 26/04/2023 01:08:43

\section{Интернет-источники}

Derzhavnost' i osobyy put' Rossii, Levada-Tsentr, 2016, http://www.levada.ru/2016/12/12/derzhavnost-i-osobyj-put-rossii

Doveriye politikam, VTSIOM, 2019, YAnvar', https://wciom.ru/news/ratings/doverie_politikam

Perelom v soznanii uzhe proizoshel, https://newsland.com/user/4297807604/content/perelom-v-soznanii-uzhe-proizoshel/6597030

http://obozrevatel.com/politics/98237-doverie-rossiyan-k-putinu-za-god-vyiroslo-s-55-do-79.htm

Reyting doveriya k Putinu vernulsya k urovnyu 2013 goda, „Ведомости”, 04.10.2018, https://www.vedomosti.ru/politics/news/2018/10/04/782769-reiting-doveriya-k-putinu 